\title{
Ovarian Volume And Antral Follicle Count Versus Serum FSH measurement in assessment of Ovarian Reserve
}

\author{
Dr. Archana Kumari Sharma ${ }^{1}$, Dr.Kanika Chandra ${ }^{2}$, Dr. Rajrani Sharma ${ }^{3}$ \\ Dr.Sanchita Dashora ${ }^{4}$ \\ Senior Resident ${ }^{1,2}$, Senior Professor \& $\mathrm{HOD}^{3}$, Assistant Professor ${ }^{4}$ \\ Department of Obstetrics and Gynaecology, Pacific Medical College and Hospital, \\ Udaipur, Rajasthan, India
}

\begin{abstract}
:
Background The presence of a wide range of tests of ovarian reserve suggests that no single test provides a sufficiently accurate result. Many tests are used without reference to an evidence base.So far, individual studies conducted on these tests are too small to give precise estimates of prognostic accuracy.

Objective: The current study was designed to compare ovarian volume\& antral follicle count (A.F.C) \& day 3 FSH level, with respect to their ability to predict ovarian response of infertile women to ovulation induction agents

Material and Methods: This is a prospective observational study in which 52 infertile women who were attending the Obst \& Gynae Dept,PMCH UDAIPUR, were recruited. Blood samples were collected on day $2 /$ day 3 for assessment of Se. FSH and TVS were done for antral follicle count and ovarian volume. Induction of ovulation was done for three successive cycles. Clomiphene citrate $100 \mathrm{mg} 10 \mathrm{D}$ was given from day 2 to 6 , and patients were followed up with serial USG measurements for the dominant follicles $(>$ or $=18 \mathrm{~mm})$. Patients with no dominant follicle in the 1 st cycle were subjected to the 2 nd and $3^{\text {rd }}$ cycle of clomiphene $100 \mathrm{mg} 1 O \mathrm{OD}$ from day 2 to day 6 with Inj HMG 150 IU given i.m. starting from day 8 and every alternate day until at least one leading follicle attained $\geq 18 \mathrm{~mm}$.

Results: In this study the results showed that AFC has a higher predictability for successful induction i.e. when $A F C<10$; the success rate was $17.7 \%$, while when $A F C>10$; the success rate was $57.142 \%$ which shows high significant difference.The next predicting factor was ovarian volume, when $<3 \mathrm{ml}$; the chance of success was very poor (zero), while when volume is $3-9 \mathrm{ml}$; the success rate was $44.11 \%$ \& when volume $>9 \mathrm{ml}$; the success rate was $62.5 \%$. While day $3 \mathrm{FSH}$ had the lowest predictability, when $\mathrm{S}$.FSH $<10 \mathrm{~m} \mathrm{IU} / \mathrm{ml}$; the success rate was $41.26 \%$, while when FSH > $10 \mathrm{~m} \mathrm{IU} / \mathrm{ml}$; the success rate was $33.33 \%$ which does not make much significant difference.

Conclusion: We concluded from our study that antral follicle count and ovarian volume are effective predictors of ovarian response being superior to complex and time consuming endocrine tests.

Keywords: AFC(Antral Follicle Count), AR (Assistted Reproduction), HMG(Human Menopausal Gonadotropin) OR(Ovulatory Response), S.FSH (Serum Follicle Stimulating Hormone), TVS(Transvaginal Ultrasound)
\end{abstract}

\section{Introduction}

Infertility has emerged as a serious health problem in India. This has led to an increasing demand for assisted reproduction technologies. This involves ovulation induction with various stimulation protocols. Not all the patients who are subjected to ovulation induction show favorable response-some may result in poor ovarian response(OR). Research on infertility has evolved with constant studies and technological advances due to the increase of infertile couples who seek assisted reproduction (AR) services.[1,2] The recruitment and development of multiple ovarian follicles are key to treatment[3,4]The correct assessment of the ovarian reserve is a central issue in the management of patients with infertility.[1,3,5]The goal is to predict the chances of response to the induction and select the "optimal" dose for the ovarian hyperstimulation.[3,6] .Female reproductive aging is a process that follows the generally accepted theory that over time, oocytes decrease in quantity and quality and do not regenerate [7]. The number of human oocytes in a female peaks at 6-7 million during fetal life (around mid gestation), followed by profound atresia; approximately 1-2 million oocytes are present at birth, 300,000-500,000 at the start of puberty, and 1,000 at 51 years of age, which is the average age of menopause [8]. Factors such as genetics, lifestyle, environment, and medical issues, including endometriosis, ovarian surgery, chemotherapy, and radiation, can influence the quantity and quality of a woman's oocytes [9]. Although this reproductive decline occurs with age, there is significant variation in fertility among women of similar age, which highlights the unpredictability and individuality of the reproductive aging process [10] Many hormones and ultrasound measurements have been assessed as a marker of ovarian reserve [11]. Biochemical 
markers identified are FSH , inhibin B, AMH, and estradiol. Biophysical markers include AFC and ovarian volume [12].

Many researchers have used single as well as multiple markers to assess the ovarian reserve. So we planned this study to assess the predictive values of biophysical (antral follicle count and ovarian volume) and biochemical markers (Se. FSH) in identifying poor ovarian reserve in Indian population.

\section{Materials and Methods}

This is a prospective cross-sectional study including 52 women diagnosed with infertility and seeking management in the form of induction of ovulation and timed intercourse/IUI or IVF at PMCH UDAIPUR

Inclusion criteria: Apparently healthy infertile women less than 40 years of age having ovulatory factor infertility willing to participate in the study with written consent.

Exclusion criteria: Patients excluded those who were having an ovarian cyst or follicle measuring more than $10 \mathrm{~mm}$ on the day of measuring the $\mathrm{AFC}$, in order not to bias the basal $\mathrm{AFC}$ or the number of leading follicles counted to detect response. history of ovarian surgery, endometrioma excision or ovarian drilling to exclude the effect of the surgery on the ovarian reserve.

All the patients prior to the start of induction of ovulation program were subjected to full history taking and systemic clinical examination to assess the general condition and local pelvic examination. All preliminary investigations including the thyroid profile and tubal patency test were done.

\section{Sample Collection}

A basal cycle day 2-3 FSH was measured from blood in all patients. AFC and ovarian volume were determined on day 2 of the cycle using transvaginal ultrasound (TVS). AFC was determined during transvaginal scanning using a $6.5 \mathrm{MHZ}$ vaginal probe. The follicles visualized and counted by TVS are $2-10 \mathrm{~mm}$ in diameter. To determine the diameter of the follicle, the mean of measurements in two perpendicular directions was taken.The volume of each ovary was calculated by measuring in three perpendicular directions and applying the formula for an ellipsoid: D1x D2 $\times$ D3 $x \pi / 6$. Serum FSH concentration was measured using commercially available kits by a two - site sandwich immune-assay.FSH assay is standardized against the World Health Organization 2nd International Standard reference material

\section{Ovulation induction}

All the 52 patients were subjected to ovulation induction

First cycle -Ovulation induction was done with standard stimulation protocol of Clomiphene Citrate $100 \mathrm{mg}$ 1OD from day 2 to 6 , and patients were followed up with serial USG measurements until at least one leading follicle attained $>18 \mathrm{~mm}$.

Second cycle and third cycle - Ovulation induction was done with Clomiphene100 mg 1OD from day 2 to 6 with Inj HMG150 IU given i.m. starting from day 8 and every alternate day until at least one leading follicle attained $>18 \mathrm{~mm}$.

Follow up All patients were followed up by follicular monitoring with vaginal ultrasonography starting on the 8th day of the cycle and then every other day until Inj HCG 10,000 IU was administered as a single I.M injection to trigger ovulation when at least one leading follicle attained $>18 \mathrm{~mm}$. Number of dominant follicles ( $=14 \mathrm{~mm}$ ) at the time of HCG administration was counted to analyze the result of ovulation induction. Patients with three or more follicles in 1st cycle were taken in group 1.

Patients with less than three follicles in 1st cycle were taken in group 2. Patients of group 2 who did not conceive were subjected to 2 nd cycle of ovulation induction. In the second-cycle ovulation-induction was done with clomiphene citrate $100 \mathrm{mg}$ from day 2/day 3 for 5 days with Inj HMG 150 IU. given i.m. on day 8, and then every alternate day until Inj HCG 10,000 IU was administered as a single I.M injection to trigger ovulation, when at least one leading follicle attained $>18 \mathrm{~mm}$. . If the patient did not conceive even in $2^{\text {nd }}$ cycle were subjected for $3^{\text {rd }}$ cycle.

Patients developing less than three follicles at end of third cycle were considered as poor response 


\section{Results}

Table 1 shows Study group characteristics

\begin{tabular}{|l|l|}
\hline $\begin{array}{l}\text { Age } \\
\text { <35yrs }\end{array}$ & $\mathbf{3 6}$ \\
>35 Yrs & $\mathbf{1 6}$ \\
\hline Type Of Infertility & \\
Primary & 46 \\
Secondary & 06 \\
\hline Duration Of Infertility & \\
<5yrs & 22 \\
$>$ 5yrs & 30 \\
\hline
\end{tabular}

Table 2 shows Relationship between AFC and success rate of induction of ovulation per cycle

\begin{tabular}{|l|l|l|l|l|}
\hline Afc & Number Of Subjects & $\%$ & $\begin{array}{l}\text { Success Rate Of } \\
\text { Induction } \\
\text { Ovulation } \\
\text { No. Of Cycles }\end{array}$ & $\begin{array}{l}\text { Of } \\
\text { Of }\end{array}$ \\
\hline$<\mathbf{4}$ & 2 & 3.84 & $\begin{array}{l}\text { Zero } \\
1 / 6 \text { (Cycles) }\end{array}$ & $\begin{array}{l}0 \% \text { To } \\
\text { Clomiphene }\end{array}$ \\
\hline $\mathbf{5 - 1 0}$ & 15 & 28.84 & $8 / 45$ (Cycles) & $17.7 \%$ \\
\hline$>\mathbf{1 0}$ & 35 & 67.30 & $60 / 105($ Cycles $)$ & $57.142 \%$ \\
\hline
\end{tabular}

For each subject 3 treatment cycles are tried $\mathrm{p}<0.001$ (highly significant)

Table 3 shows Relationship between ovarian volume and success rate of induction of ovulation per cycle

\begin{tabular}{|c|c|c|c|c|c|}
\hline Ovarian Volume & No. Of Subjects & $\%$ & $\begin{array}{l}\text { Success Rate } \\
\text { Induction } \\
\text { Ovulation } \\
\text { No. Of Cycles }\end{array}$ & $\begin{array}{l}\text { Of } \\
\text { Of }\end{array}$ & $\%$ \\
\hline$<3$ & 2 & 3.84 & Zero/6 (Cycles) & & 0 \\
\hline $3-9$ & 34 & 65.38 & 45/102(Cycles) & & $44.11 \%$ \\
\hline$>9$ & 16 & $30.76 \%$ & 30/48(Cycles) & & $62.5 \%$ \\
\hline
\end{tabular}

Table 4 shows Relationship between day 2-4 serum FSH level \& success rate of induction of ovulation per cycle

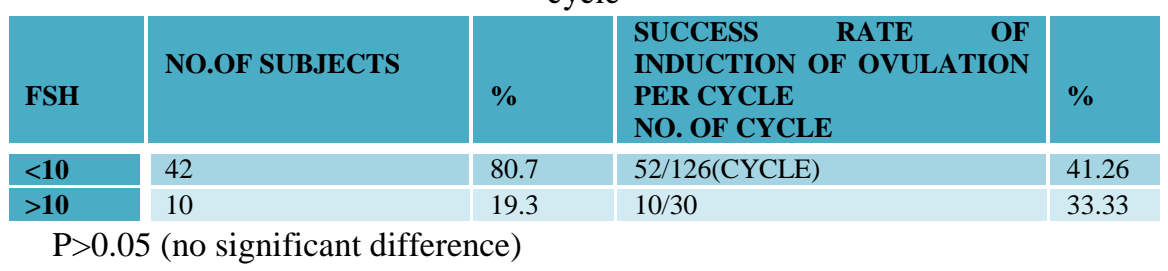

\section{Discussion}

Reproductive ageing is thought to be dictated by a gradual decrease in both the quantity and the quality of the oocytes and follicles held within the ovaries [13, 14]. A gradual decrease with advancing age in the number of sonographically detectable antral follicles has been shown in many studies [15]. In recent years several papers have been published concerning the relation between the antral follicle count (AFC, defined as the total number of antral follicles, sized $2-5$ or $2-10 \mathrm{~mm}$, present in both ovaries) and the ovarian response in IVF [16], as well as the occurrence of the menopausal transition, indicating that this parameter relates strongly to the quantitative aspects of ovarian reserve. Recently Hendriks et al. [17], published a meta-analysis on the $\mathrm{AFC}$ as a predictor for poor ovarian response and concluded that AFC is an adequate test for the prediction of poor ovarian response, compared to FSH. The high intercycle stability of AFC and its potentially likely attractive cost features are likely to make this test rather attractive for routine practice The present study showed that the AFC is a valuable test that can be used in infertile women to assess their ovarian reserve and 
thus chances of their response to ovulation induction. Studies conducted by Klinkert et al. on antral follicle count in 2005 demonstrated that AFC $>5$ follicles was a better predictor of ongoing pregnancy [18] which is almost similar to our study.

Ovarian volume has been considered as a test of ovarian reserve by various authors. Syrop et al. in their study on infertile women undergoing the first cycle of IVF concluded that total ovarian volume was a significant predictor of cycle cancelation [19]. Our study also show that ovarian volume can also be used as predictive marker for successful ovulation induction. Day 3 serum FSH concentrations were not significant in predicting poor ovarian reserve/response which is similar to Syrop et al. in their study on infertile women undergoing the first cycle of IVF concluded that basal FSH was not significant predictor of cycle cancelation [19] but study done by Jaiswar S. P. et al concluded Day 3 serum FSH concentrations were significant in predicting poor ovarian reserve/response. Based on their study, it could be predicted that infertile women with serum FSH values>7.10 IU/L are at high risk of developing poor response to ovarian stimulation [20] which is in contrast to our study. This could be explained by the fact that limitations of measurement of basal FSH include the lack of a clear cut-off point, monthly variations and disparities between different laboratory assays.[21]

\section{Conclusion}

Screening for the ovarian reserve is fundamental component of the initial infertility evaluation. An improved ascertainment of the ovarian reserve status may help one optimize the planned therapeutic intervention, and thus minimize the emotional and financial strains imposed upon couples seeking fertility treatment.

\section{Acknowledgement}

The authors are thankful to the patient and her attendants for their consent to publish the case .

\section{Conflict of interest}

The authors declare no conflict of interest.

\section{Source of funding}

\section{None}

\section{References}

[1]. Vural B, Cakiroglu Y, Vural F, Filiz S. Hormonal and functionalbiomarkers in ovarian response. Arch Gynecol Obstet 2014;289(6):1355-1361

[2]. Galliano D, Bellver J, Díaz-García C, Simón C, Pellicer A. ART and uterine pathology: how relevant is the maternal side for implantation Hum Reprod Update 2015;21(1):13-38

[3]. Castro EC, Borges ALF, Rezende KN, Amaral WN. Antral follicle count in predicting appropriate dose of gonadotropin in in-vitro fertilization cycles. Reprod Clim. 2014;29(3):136-14

[4]. Beltadze K, Barbakadze L. Ovarian reserve in women of late reproductive age by the method of treatment of PCOS. Iran JReprod Med 2015;13(5):263-268

[5]. Bentzen JG, Forman JL, Larsen EC, et al. Maternal menopause as a predictor of anti-Mullerian hormone level and antral follicle count in daughters during reproductive age.HumReprod 2013;28(1):247-255

[6]. Broer SL, van Disseldorp J, Broeze KA, et al; IMPORT study group added value of ovarian reserve testing on patient characteristics in the prediction of ovarian response and ongoing pregnancy: an individual

[7]. patient data approach. Hum Reprod Update 2013;19(1):26-36

[8]. Testing and interpreting measures of ovarian reserve: a committee opinion. Practice Committee of the American Society for Reproductive Medicine. Fertil Steril 2012;98:1407-15. [PubMed] [Full Text]

[9]. Faddy MJ, Gosden RG, Gougeon A, Richardson SJ, Nelson JF. Accelerated disappearance of ovarian follicles in mid-life: implications for forecasting menopause. Hum Reprod 1992;7:1342-6. [PubMed]

[10]. Female age-related fertility decline. Committee Opinion No. 589. American College of Obstetricians and

[11]. Gynecologists. Obstet Gynecol 2014;123:719-21. [PubMed] [Obstetrics \& Gynecology]

[12]. te Velde ER, Pearson PL. The variability of female reproductive ageing. Hum Reprod Update 2002;8:141-54

[13]. Van der steeg JW et al. Prediction models in reproductivemedicine.

[14]. Creus M, et al. Day 3 serum inhibin B and FSH and age aspredictors of assisted reproduction treatment outcome. hum Reprod.2000;15(11):2341-6.

[15]. Te Velde ER, Dorland M, Broekmans FJ: Age at menopause as a marker of reproductive ageing. Maturitas 1998, 30:119-125.

[16]. Te Velde ER, Pearson PL: The variability of female reproductive ageing. Hum Reprod Update 2002, 8:141-154.

[17]. Van der Meer M, Hompes PGA, de Boer JAM, Schats R, SchoemakerJ: Cohort size rather than follicle-stimulating hormone sthreshold level determines ovarian sensitivity in polycysticovary syndrome. J Clin Endocrinol Metab 1998, 83:423-426

[18]. Bancsi LFJMM, Broekmans FJM, Eijkemans MJC, de Jong FH, habbemaJD, te Velde ER: Predictors of poor ovarian response in in vitrofertilization: a prospective study comparing basal markers of ovarian reserve. Fertil Steril 2002 77:328-336

[19]. Hendriks, DJ; Mol, Bancsi, Broekmans, FJM . Antral follicle count in the prediction of poor ovarian response and pergnancy after in - vitro - fertilization. Fertil Steril. 2005; 83:291 - 301

[20]. Klinkert R, Broekmans FJM, Looman CWN, et al. The antralfollicle count is a better marker than basal follicle-stimulating hormone for the selection of older patients with acceptabl epregnancy prospects after invitro fertilization. Fertil Steril.2005;83:8114 [2005 by American Society for Reproductive Medicine].

[21]. Syrop CH, Dawson JD, Husman KJ, et al. Ovarian volume may predict assisted reproductive outcomes better than follicle stimulatinghormone concentration on day 3. Hum Reprod.1999;14(7):1752-6.

[22]. Jaiswar S. P., Natu S. M , Sujata •Sankhwar P. L., Manjari Gupta Prediction of Poor Ovarian response by Biochemicaland Biophysical Markers: A Logistic Regression Model The Journal of Obstetrics and Gynecology of India (November-December 2015) 65(6):411-416

[23]. Scott RT Jr, Hofmann GE. Prognostic assessment of ovarian reserve. Fertil Steril 1995;63:1-11. 